\title{
Comparative Advantages of Alternative Crops: A Comparison Study in Ben Tre, Mekong Delta, Vietnam
}

\author{
Viet Van Hoang, Khai Tien Tran \\ University of Economics Ho Chi Minh City, Vietnam
}

\begin{abstract}
This study aims to measure the comparative advantages of alternative crops of rice, coconut, and pomelo as the key indicators for crop cultivation choices by using DRC, SCB, and other competitiveness indicators in PAM model with sensitivity analysis. The results indicate that pomelo fruit obtains the strongest competitiveness, coconut has the medium competitiveness, and rice has the weakest competitiveness. Coconut crop is the most stable while rice is the most sensitive to climate and market changes. This may suggest that farmers and policymakers should convert from rice crop into and adopt pomelo and coconut crops for more effective economic and sustainable benefits. However, this conversion should take account of the soil transferring costs and the initial cultivation costs of pomelo and coconut crops. Production indicators and trade indices seem to indicate contradictory rankings of competitiveness. The result, however, is still consistent with the economic theory.
\end{abstract}

\section{Keywords}

Vietnam, agriculture, crop choices, comparative advantage, sensitive analysis.

Hoang, V. V. and Tran, K. T. (2019) "Comparative Advantages of Alternative Crops: A Comparison Study in Ben Tre, Mekong Delta, Vietnam", AGRIS on-line Papers in Economics and Informatics, Vol. 11, No. 1, pp. 35-47. ISSN 1804-1930. DOI 10.7160/aol.2019.110104.

\section{Introduction}

The agricultural production system is affected by various factors such as dynamic policies, economic resources, market situations, and environmental conditions. This leads to challenges to identify the comprehensive comparative advantage of an agricultural production system and difficulties to make crop choice decisions. Moreover, the conventional economic wisdom advocates that a country should utilize its scarce resources by specializing in agricultural commodities with stronger comparative advantages and creating higher values added and social welfare. Hence, a central part of economic theory is to search for efficient and summary tools to measure the comparative advantages of agricultural commodities, assess the policy impact on social welfare and estimate the future performance of the commodity subject to the potential scenarios.

Agriculture is a key economic sector in Vietnam when it accounts for $12.2 \%$ GDP, $17.8 \%$ of export, and $41.9 \%$ of employment in 2016 (General Statistics Office, 2018). The country has various public policies to enhance the stability and growth of agricultural sector at both production and market levels. The Mekong Delta is the main agricultural production region of Vietnam with strategic sectors such as rice, fruits, vegetables, and aqua-products. These key agricultural products, however, have become less profitable and less competitive due to input cost increases, oversupplies, and environmental food-prints. These issues compel farmers, enterprises, and policymakers to urgently identify and adopt the most profitable, suitable, and sustainable crops in the same arable lands with the similar natural and social conditions based on competitiveness indicators.

Ben Tre province is chosen for this empirical and policy analysis as it represents agricultural characteristics of the Mekong Delta in Vietnam. The province has advantages in agriculture thanks to appropriate natural conditions such as fertile soil and abundant water resource. Ben Tre has diverse agro-ecological characteristics and can be divided into three main ecological zones: fresh, brackish and saline water. Rice and fruit crops are mainly based on freshwater zone while coconut is easily planted on fresh, brackish and saline water condition. Nevertheless, three crops can be alternatively 
grown in the same land they are dominant crops of Ben Tre province. Under the impact of climate change, areas affected by brackish and saline water increase while lack of fresh water in dry season reduces rice and fruit production capacity of the province. Under these changes, raising agricultural plan and policy questions are how to change the crop cultivation structure to get a better adaptation to climate change, market variations, and to ensure higher benefits to farmers.

To examine the question, this study aims to measure and compare the comparative advantage of rice, pomelo, and coconut crops in the same arable lands of Ben Tre by using Domestic resource cost (DRC), Social cost-benefit (SCB) models, and other competitiveness indicators in Policy Analysis Matrix (PAM). The sensitive analysis is used to estimate the elements' changes in the comparative advantages of these sectors based on the different assumed scenarios of natural and market conditions. These crops are selected since rice is a key representative of the food sector, pomelo is a significant representative of fruit sector, and coconut is a good representative of the agricultural material sector as an essential input for the coconut processing industry in Vietnam. In addition, the paper analyses the consistency of production indicators and trade indices in measuring the competitiveness. The results should make both academic and practical contributions to policymakers, enterprises, and scientists. First, the study identifies, compares, and estimates the comparative advantages of alternative crops for farming choice and agricultural policy decisions. Second, the result extends the empirical studies of the literature and approach in the case of transition economy as Vietnam. Third, the paper contributes to the economic theory in measuring by, comparing, and defining comparative advantage approaches.

\section{Literature review}

There are different frameworks to measure comparative advantage at different levels. Buckley et al. (1988) categorize the measures of competitiveness into three groups: competitive performance, competitive potential, and competitive process for each level of analysis such as country, region, industry, firm and commodity. In the economic literature, there are two approaches for comparative advantage assessment of agriculture. One is the domestic resource cost or the equivalent benefit-cost analysis such as $\mathrm{DRC}, \mathrm{SCB}$ and other competitiveness indicators in PAM model and the second is international trade approach such as Revealed comparative advantage
(RCA) of Balassa (1965), Relative trade advantage (RTA) of Vollrath (1991), and Normalized revealed comparative advantage (NRCA) of Yu et al. (2009) (Cai and Leung, 2009; Latruffe, 2010; Gorton et al., 2013). Latruffe (2010) clarifies the approaches into two groups of trade measures and strategic management measures. Trade measures include real exchange rate and purchasing power parities, revealed comparative advantage, and other export and import indices. Strategic management measures are cost measures, profitability, productivity, and efficiency. Cost measures involve domestic resource costs, social cost-benefit, and agricultural production costs.

DRC is a measure of real opportunity cost in terms of total domestic resources of producing a net marginal unit of foreign exchange (Bruno, 1972). According to Tsakok (1990), the concept of opportunity cost is used to assess comparative advantage and there are four stages to evaluate comparative advantages such as (i) determining the opportunity cost of exchange rate; (ii) calculating the value-added component in foreign and border prices; (iii) computing the cost of the primary production factors or domestic resources used in production; (iv) and comparing the domestic resource cost and net benefits. He explains that the process of comparing the costs with benefits for a production activity is employed as an indicator of efficiency and the most popular framework related to this calculation is domestic resource cost. Gorton et al. (2001) add that DRC is useful to measure social profits when activities producing different outputs are compared for their efficiency and it compares opportunity costs of domestic production with the value added it creates.

Masters and Winter-Nelson (1995) argue that DRC ratio is, however, based on the cost of non-tradable inputs and it understates the competitiveness of activities that use mainly such domestic factors in comparison to those that rely more on tradable inputs. To overcome this shortcoming, these authors propose the social cost-benefit (SCB) ratio with the same data that is a generally superior measure of social profitability.

Policy analysis matrix is proposed and completed by Pearson et al. (1976) and Monke and Pearson (1989) based on DRC approach to address the issues. According to Michalek (1995), PAM obtains several critical advantages as follows: (i) the model is specific enough to account for the most important economic relations between the macro and micro indicators with time and data constraints; (ii) it is appropriate to analyze 
the price and production efficiency; (iii) it may assess the impact of policies on the incomes of farmers; (iv) the model can identify the magnitude of the income transfers between producers, consumers and policy's budget; (v) it measures the key coefficients relating to the level of protection and comparative advantage of a sector; and (vi) the results can be properly disaggregated between different types of firms, regions, and products. Despite advantages, as in all quantitative methods, the model has limitations: first, PAM is static model; secondly, perfect substitution between the domestic and foreign tradable commodities is usually and strictly assumed; third, only under certain restrictive behavioral assumptions (such as supply and demand elasticities equal to zero) are estimated income transfers identical to producer and consumer surplus; and fourth, plentiful and nonmarket data is needed to examine the performance of a given production system. In summary, PAM yields various indicators (i) first to measure the comparative advantage of a sector; (ii) second to assess the impacts of government policies, market failures, and economic performance elements; and (iii) third to assess the dynamics and trends of comparative advantages based on the scenario analysis and time data. It is remarkably useful and meaningful that PAM model can compare both the different production systems for the identical outputs and the various outputs from the same production systems.

Yao (1997a, 1997b) evaluates the costs and benefits of the Thai agricultural diversification policy for three competitive crops of rice, soybeans and mung beans in two provinces by PAM model. The result indicates that rice sector is more competitive than soybeans and mung beans and government policy may cause efficiency reduction. Estudillo et al. (1999) measure the comparative advantage in the rice production in the Philippines for the three decades and find out that the Philippines achieves the comparative advantage in rice production due to new technology in the early period but it lost the comparative advantage by 1990 . DRC ratio may be also employed to compare the competitiveness of one country to others as well. Gorton et al. (2001) assess the competitiveness of agricultural productions in Bulgaria and the Czech Republic in comparison with other the EU by DRC ratio and revealed comparative advantage. The study indicates that Czech and Bulgarian cereal producers are competitive at the world and at EU market prices by DRC ratio. However, they do not achieve revealed comparative advantage in trade with the EU because of trade restriction policy. Liefert (2002) assesses Russia's comparative advantages of agricultural output and input productions and indicates that the country has an advantage in agricultural inputs compared with its agricultural outputs and also has an advantage in bulk crops in comparison with meat production.

Mohanty et al. (2003) measure the comparative advantage of Indian cotton production by PAM and show that without the intervention of government, cotton farmers may move away from cotton to crops for higher income. Makosholo and Jooste (2006) assess the comparative economic advantage of irrigated longterm crops such as cherries, peaches, apples, and asparagus and conclude that the sectors have been subsidized by different government's policies, especially the impact of the exchange rate. The authors also indicate that the policies of land and water may have a remarkable influence on crops to reduce poverty. Mane-Kapaj et al. (2010) argue the opposition of comparative advantage to profit. They assess the comparative advantage of olive oil production in Albania and show that the sector is profitable while does not have a comparative advantage. Zheng et al. (2013) state that government's policy may impact on the comparative advantages of agricultural sectors in China at different levels. The intervention enhances comparative advantage in wheat production while not significantly improves the comparative advantages of soybean and corn. Adeoye and Oni (2014) analyze the competitiveness and effects of government policies on plantain production systems in Nigeria. The results indicated that plantain production was privately and socially profitable in all the productions systems.

$\mathrm{DRC}, \mathrm{SCB}$, and other economic indicators are, however, static models and they cannot capture the prospective shifts in input and output prices, productivity, and another natural, social and market conditions. The models, therefore, may generate unrealistic results in the dynamic sense and potential biased against public policies (Mane-Kapaj et al., 2010; Yao 1997a). The models, however, may estimate the comparative advantage dynamics in the future based on the assuming scenario or time data as the third function of the model. Sensitivity analysis provides a tool for assessing the impact of changes in assumptions and errors (such as exchange rates, global prices, production yield change due to environmental degradation) in estimating profitability and projecting competitiveness. It can be applied to both private and social estimations (Monke and Pearson, 
1998; Gorton et al., 2006). According to Monke and Pearson (1989), there are two ways of sensitive analysis: the first is involved to the calculation of breakeven values for social profitability with other fixed initial values and the second is the elasticity of social profitability with respect to a particular parameter with a change in the parameter of interest by an arbitrary percentage. Scholars, moreover, estimate the comparative advantage indicators based on the different scenarios which are assumed to happen potentially in the future, such as regional and global integrations, market conditions, natural environments, and government policies (Yao, 1997b; Gorton et al., 2006). Morrison and Balcombe (2002), moreover, remark that the traditional sensitivity analyses are relatively involved in bootstrapping technique. Thus, the sensitivity analyses can be performed by testing how estimates change when parameters or variables of interest are varied. In conclusion, though DRC, SCB, and other indicators in PAM model are the basic and traditional models, if well combining with sensitive analysis methods, they can be significantly and academically employed to measure competitiveness and choose the alternative sectors, to compare the comparative advantage between countries, and to analyze the impacts of policy, market, globalization, and environmental changes on the comparative advantage and profitability of agricultural sectors.

\section{Materials and methods}

\section{Analytical framework}

The basic PAM contains two cost columns, one for tradable inputs and the other for domestic factors. Intermediate inputs (such as fertilizer, pesticide, purchased seed, compound feed, electricity, transportation, and fuel) are grouped into the tradable-input and domestic factor components. This process of disaggregation of intermediate goods or services separates intermediate costs into four categories including (i) tradable inputs, (ii) domestic factors, (iii) transfers (taxes or subsidies), and (iv) nontradable inputs. The non-tradable inputs themselves must be further disaggregated so that ultimately all component costs are classified as tradable inputs, domestic factors, or transfers (Table 1).

There are various indicators in PAM model to measure comparative advantage, policy and market failure, and social transfer. This study mainly uses the private and social competitiveness indicators of production systems which can be presented as follows (Monke and Pearson, 1989; Beghin and Fang, 2002; Adeoye and Oni, 2014):

\section{Private profitability (PP - D)}

This index shows the competitiveness of enterprises or actors in the agricultural production system given available technology, input and output prices, and government policy. The term private refers to observed revenues and costs in showing actual market prices received or paid by farmers, merchants, or processors in the agricultural system. The private profitability of agricultural commodity $j$ can be simply calculated as follows:

$$
\begin{aligned}
P P= & D=A-(B+C)= \\
& P_{j}^{p}-\left\{\sum_{i=1}^{k} a_{j i} P_{i}^{p}+\sum_{i=k+1}^{n} a_{j i} P_{i}^{p}\right\}
\end{aligned}
$$

where, $a_{j i}(i=k+1$ to $n)$ are the coefficients for domestic resources for product $j ; a_{j i}(i=1$ to $k$ ) are the coefficients for tradable inputs for product $j$. $P_{j}^{p}$ is the private price of product $j . P_{i}^{p}$ is the private price of input $i$. The $D>0$ indicates that production

\begin{tabular}{lcccc}
\hline & Revenues & \multicolumn{2}{c}{ Costs } & Profits \\
\hline Private Prices & & Tradable inputs & Domestic factors & \\
\hline Social Prices & $A$ & $B$ & $C$ & $D$ \\
\hline Divergences & $E$ & $F$ & $G$ & $L$ \\
Market failures & $I$ & $J$ & $K$ & $\mathrm{P}$ \\
Distorting policy & $\mathrm{M}$ & $\mathrm{N}$ & $\mathrm{O}$ & $\mathrm{T}$ \\
Efficient policy & $\mathrm{Q}$ & $\mathrm{R}$ & $\mathrm{W}$ & $\mathrm{X}$ \\
\hline
\end{tabular}

Note: $A$ is private revenue, $B$ is private tradable input cost, $C$ is private domestic factor cost, and $D$ is private profit. $E$ is social revenue, $F$ is social tradable input cost, $G$ is social domestic factor cost, and $H$ is social profit. $I$ is output transfer, $J$ is input transfer, $K$ is factor transfer, and $L$ is net policy transfer $(I, J, K$, and $L$ are the differences between social and private elements from market failures, distorting $\&$ efficient policies). Source: Adapted from Monke and Pearson (1989)

Table 1: The accounting structure of policy analysis matrix. 
system $j$ is profitable and competitive. A higher value of $D$ indicates stronger competitiveness of production system $j$.

\section{Social profitability $(S P-H)$}

The social profits measure social efficiency or comparative advantage of a production system as the outputs and inputs are evaluated by the social prices reflecting the scarcity values of resources. The social profit $(H)$ of agricultural commodity $j$ can be simply computed as follows:

$$
\begin{aligned}
S P= & H=E-(F+G)= \\
& P_{j}^{S}-\left\{\sum_{i=1}^{k} a_{j i} P_{i}^{S}+\sum_{i=k+1}^{n} a_{j i} P_{i}^{S}\right\}
\end{aligned}
$$

where, $a_{j i}(i=k+1$ to $n)$ are the coefficients for domestic resources for product $j ; a_{j i}(i=1$ to $k$ ) are the coefficients for tradable inputs for product $j . \mathrm{P}_{\mathrm{j}}^{\mathrm{s}}$ is the social price of product $j$. $P_{i}^{s}$ is the social price of input $i$. The $H>0$ indicates that production system $\mathrm{j}$ is socially profitable and competitive. A higher value of $H$ indicates stronger competitiveness of production system $\mathrm{j}$.

\section{Domestic resource cost (DRC)}

This indicator evaluates the relative efficiency of a domestic production by comparing the opportunity cost of the domestic production to the values added it creates. This index is especially useful to compare the relative efficiency among different products from a production system. $D R C$ can be measured by the ratio of the domestic resources costs $(G)$ to the value added $(E-F)$ in social prices (or the net foreign exchange saved by domestically producing the product):

$$
D R C=\frac{G}{E-F}=\frac{\sum_{i=k+1}^{n} a_{j i} P_{i}^{S}}{P_{j}^{S}-\sum_{i=1}^{k} a_{j i} P_{i}^{S}}
$$

The presentation of the symbols in this formula is similar to the social profitability index. $D R C<1$ means that production system $j$ is relatively social efficient and competitive, and vice versa. A lower value of $D R C$ indicates a stronger comparative advantage of production system $j$. To identify the degree of competitiveness, this study classifies DRC values of the competitive sectors into two groups: (i) smaller and equal to 0.5: indicate the strong comparative advantage, and; (ii) greater than 0.5 and smaller than unity: mean the weak comparative advantage.

\section{Social cost-benefit (SCB)}

Masters and Winter-Nelson (1995) argue that DRC ratio is, however, based on the cost of non-tradable inputs and it understates the competitiveness of activities that use mainly such domestic factors in comparison to those that rely more on tradable inputs. To overcome this shortcoming, the authors propose the social cost-benefit ratio with the same data as follows:

$$
S C B=\frac{F+G}{E}=\frac{\sum_{i=1}^{k} a_{j i} P_{i}^{S}+\sum_{i=k+1}^{n} a_{j i} P_{i}^{S}}{P_{j}^{S}}
$$

The domestic production is competitive when $S C B$ value is less than the unity as it reveals that total input costs are less than the revenue derived from the good. The opposite is true for the $S C B$ greater than the unity and $S C B$ of less than 0 does not exist. To identify the degree of competitiveness, this study also classifies $S C B$ values of the competitive sectors into two groups: (i) smaller and equal to 0.5 : indicate the strong comparative advantage, and; (ii) greater than 0.5 and smaller than unity: mean the weak comparative advantage.

PAM model also provides various indicators measuring the policy protection, market failure, and benefit transferring such as Nominal Protection Coefficient (NPC), Effective Protection Coefficient (EPC), Profitability Coefficient (PC), and Subsidy Ratio to Producers (SRP).

\section{Data and social price description}

Data sources and sampling: The data for producing PAM indicators and value chain performance for the agricultural crops are productivities, input quantities, input market prices, output market prices. Moreover, the data on transportation cost, processing cost, storage cost, port cost, subsidies, tariffs, exchange rate, and others are needed to derive social prices. The primary data are collected directly in the fieldworks by structured and semi-structured questionnaires for all actors in the value chains including 430 farmers, 50 middle traders, 20 trading and processing companies, 20 wholesales and export companies, and 50 retailers in pomelo, coconut, and rice value chains in Ben Tre province. The secondary data is collected from different resources such as WB, FAO, Vietnam's GSO, Vietnam's Customs, Vietnam's State Bank, and other reports and news articles.

Real exchange rate estimation: The real exchange rate is a key ratio to transfer the private revenue into social revenue. According to Bui et al. (2017), Vietnam real exchange rate has been significantly overvalued recently, most notably due to Vietnam's relatively high inflation rate. Mai (2007), based on IMF data, shows that the real exchange rate is relatively higher than the nominal official exchange rate over time. The IMF (2016) and Darvas (2012) 
indicate that the real effective exchange rate of Vietnam increases over time in comparison with the index in 2010. This study uses the data of consumer price indices (CPI) of Vietnam and the USA from FAOSTAT and the data of the official exchange rate from $\mathrm{WB}$ to estimate the real exchange rate with the reference of Mai (2007), IMF (2016), and Bui et al. (2017). The result shows that, in 2016, the ratio of Vietnam's CPI to the USA's CPI is 1.36. The official exchange rate of Vietnam in 2016 is 21,935 VND per USD ${ }^{1}$. As the result, Vietnam's real exchange rate is 29,815 VND per USD. This means that Vietnam undervalues the exchange rate or overvalues the local currency of VND.

Tradable inputs and domestic factors: Following Yao (1997b), this study separates the tradable input cost into detail tradable inputs and domestic factors with the principals: (i) the service and logistic cost are relatively higher in Vietnam than Thailand; (ii) the local goods and service cost (such as electricity, water, and seed) are also divided into detail domestic factors and tradable inputs; and (iii) the proportions of tradable inputs and domestic factors of various crops are different and dependent on the origin and characteristics of the inputs. Specifically, though seed (purchased), chemical pesticide, chemical fertilizer, and fuel are the tradable inputs, they consist of various domestic costs such as port charge, unloading, transporting, warehouse, and markup and the domestic products obtain significant market shares. Electricity, water, and contracted services are domestic factors they, however, employ some tradable goods such as pipe, pump, wire, machines, and equipment. Pomelo and coconut need to have the initial investments and the farmers have no income in the period. The cost, therefore, will be accounted as the depreciation for the harvesting period. The initial investment costs also include both tradable inputs and domestic factors.

Social prices for outputs and tradable inputs: The social prices for output and tradable inputs are, in general, measured as border prices (export/ import parity prices) and adjusted to the farm level (Gorton et al, 2000). Based on the approach of Yao (1997b), the social input cost will be calculated from the private input cost which includes the private tradable input cost and the private domestic factors. The private tradable input cost is transferred to the social tradable input cost by excluding divergence (tax) and multiplying with the real exchange rate. The social domestic

\footnotetext{
${ }^{1}$ This official exchange rate is used to transfer the currency unit from VND to USD.
}

factors are equal to the private domestic factors. The private input price (or cost) data is collected and calculated at the farm gate from farmers, retailers, and public information.

Social prices for the agricultural outputs in this research (rice, coconut, and pomelo) will be computed as export parity prices (F.O.B) and adjusted to the farm gate level since rice, coconut, and pomelo are all export agricultural products of Vietnam. The adjustment of prices from border to farm gate takes account of port and handling charges, transport, storage, packaging, production, primary processing, and markup. The material coconut nut is mainly processed and divided into coconut fiber, coconut peat, coconut cell coal, desiccated coconut, and coconut jelly with various production processes and technology. Thus, the parity price of coconut nut will be aggregated from the parity prices of these various coconut products and materials based on the primary processing coefficients. The paddy rice and bran are processed from paddy grain with milling and polishing as processing. Thus, the parity price of paddy grain will be aggregated from the parity prices of these various paddy grain products and materials (paddy rice and bran) based on the primary processing coefficients. Moreover, the farm gate parity price of export rice type of IR50404 will be transferred into the farm gate parity price of rice type of OC10 produced in Ben Tre based on the price rate of IR50404 and OC10 paddy grain and paddy rice in the local market. The pomelo is fresh fruit and is not processed into other products with polishing and cleaning as processing. The social price for the outputs is transferred from the private price by excluding divergence (tax) and multiplying with the real exchange rate.

Land opportunity cost: The practitioners usually calculate the land opportunity cost by the sum of market rent and state land charge. According to Yao (1997b), a more precise way to compute the land opportunity cost for a crop is the best net return to the land (per hectare) of the strongest competitive crops. The net profits of rice, coconut, and pomelo will be compared. The net return of the most profitable crop will be adopted as the land opportunity cost for other crops and the net return of the second best profitable crop is the land opportunity cost for the first one. This way, however, does not take account of land transforming cost to cultivate a new crop (changing an old crop to other new crops).

Labor opportunity cost: The social cost of labor is based on the formula of Yao (1997b). It is simply 
calculated as the weighted average of the peakseason and off-peak season wage rates. However, the private prices, the weights, and the high and low seasons of the labors in the sectors of rice, coconut, and pomelo are relatively different. In the peak -season of rice cultivation, the weight is $50 \%$ and the wage is USD 11.40 (VND 250 thousand). The weight is $70 \%$ and the wage is USD 9.12 (VND 200 thousand) in the peak-season of coconut and pomelo. The authors assume that the wage is USD 3.19 (VND 70 thousand) in the off-season for all sectors.

\section{Sensitivity analysis}

In this study, the authors measure the sensitivity of the comparative advantage indicators by three scenarios: (i) Climate change: The drought and salinity intrusion in the Mekong River Delta of Vietnam in 2016, this problem makes rice yield decrease by $14 \%$, pomelo yield decrease by $5 \%$ while it causes the $1 \%$ increase of coconut yield in comparison with 2015 (calculating based on the data of Ben Tre Statistics Office, 2017); (ii) Water and land charges: The government takes the full charges of water and land (without subsidy); (iii) Parameters changes: The parameters of the comparative advantage elements such as output prices, inputs prices, and the real effective exchange rate are assumed to change in the scope of $\pm 5, \pm 10, \pm 15$ and $\pm 20 \%$.

\section{Result and discussion}

\section{Comparative advantages of the alternative crops}

Table 2 summarizes the comparative advantages of the alternative crops of rice, coconut, and pomelo in Ben Tre province, the Mekong Delta, Vietnam. The results show that, in general, these agricultural production systems obtain positive profits and comparative advantages by both DRC, SCB, and other ratios. The possible explanation for these strong comparative advantages is that these crops mainly utilize the domestic resources such as environment and labor. In addition, with the favorable environmental conditions and cheap labor cost, these agricultural production systems get relatively good profits. It is, in overall, remarkable that SCB ratios of rice, coconut, and pomelo are higher than DRC ratios (or showing less comparative advantage) but the competitiveness rankings of these alternative crops are not changed. This means that the tradable and domestic input employments of the agricultural production systems are not significantly different.
Pomelo achieves the strongest comparative advantage with DRC ratio of 0.13 and SCB ratio of 0.15 . The crop creates the highest private profitability with the value of USD 16,844 (VND 369,464,491) per hectare and the highest social profitability with the value of USD 25,495 (VND 559,225,182) per hectare. The main reason is that Ben Tre has the best suitable natural conditions to cultivate pomelo, especially Da Xanh cultivar. The product of Da Xanh pomelo becomes recently preferred and specialty with the limited supply and famous brand name. In addition, consumers are willing to pay higher prices for the product, especially for offering gifts or worshiping God and the ancestors. Besides, change of diet preference of urban consumers from staple food to fruits also leads to a higher demand for this special fruit.

Coconut crop obtains the strong competitiveness with DRC ratio of 0.38 and SCB ratio of 0.42 . Coconut crop is less profitable than pomelo crop with the private profitability of USD 1,484 (VND 32,555,867) per hectare and the social profitability of USD 3,415 (VND 74,915,361) per hectare. The coconut is less lucrative and has the lower output value in comparison with pomelo. Notably, the coconut has an additional comparative advantage due to generating a coconut processing cluster in Ben Tre with various processed products such as coconut milk, virgin coconut oil, desiccated coconut, coir nets and coconut fiber, coconut peat, and coconut shell coal for both domestic and export market. The production sector becomes the key industry in Ben Tre with the significant contributions of exports, employment, incomes, and taxes. An advantage of coconut is to be able to adapt to diverse cultivation conditions. Coconut tree can stand on all saline, brackish and freshwater environment and bad soil and requires minimum additional agro-chemicals and labor.

Rice crop has the weak comparative advantage with DRC ratio of 0.63 and SCB ratio of 0.71 (Table 2). The crop, however, gets relatively low profit with the private value of USD 146 (VND 3,196,934) per hectare and the social value of USD 964 (VND 21,147,271) per hectare due to low selling price in the world market. In general, despite its popularity, rice brings low output value in comparison with other crops. The agricultural production in Ben Tre province, in general, has been significantly affected by the climate changes such as the sea level increase and lack of fresh water provided from the Mekong River upstream. This reason even makes the rice production becomes less competitive in comparison with pomelo 


\begin{tabular}{llccrc}
\hline No. & Indicators & Unit & Rice & Coconut & Pomelo \\
\hline 1 & Private profitability (PP) & USD & 146 & 1,484 & 16,844 \\
2 & Social profitability (SP) & USD & 964 & 3,415 & 25,495 \\
3 & Domestic resource cost (DRC) & & 0.63 & 0.38 & 0.13 \\
4 & Social cost-benefit (SCB) & & 0.71 & 0.42 & 0.15 \\
\hline
\end{tabular}

Source: own calculation based on the primary data (2017)

Table 2: The comparative advantage indicators of rice, coconut, and pomelo in Ben Tre.

and coconut crops. Although being less competitive than pomelo and coconut, Vietnam's rice sector may obtain still the stronger comparative advantage in comparison with rice productions in other countries such as Philippines (Estudillo et al., 1999), Thailand (Yao, 1997a), Indonesia (Mantau et al., 2014), and Spain (Martinez et al., 2008).

The research also shows that the social profits of these crops are higher than their private profits. The results are relatively different from those of studies in other countries (Zheng et al., 2013; Amirteimoori and Chizari, 2008; Gorton et al., 2006; Gorton and Davidova, 2001). This result indicates that a part of the benefit of the private sector is transferred to the social sector. The calculations of NPC, EPC, PC, and SRP indicators also imply the similar results. The possible explanation is that though the water, land, and environmental charges are free for farmers Vietnam's government takes significant charges from other input and output business activities such as fertiliser, pesticide, transportation, logistics, energy, and others.

Sensitive analysis of the comparative advantage indicators

Climate changes: The Mekong River Delta in 2016 encounters the problem of the drought and salinity intrusion due to the sea level rise and the reduction of the Mekong River water flow. The problem results in the changes of production yields and make the comparative advantages of these crops change. The estimating result shows that rice does not has the private profit and competitiveness with the decrease in production yields by $14 \%$ with the negative PP value of USD 184 (VND 4,027,585). The crop still obtains the social comparative advantage with DRC value of 0.77 and SCB value of 0.82 . Though pomelo bears the 5\% reduction in yield its comparative advantage indicators is still stable. The potential explanation is that pomelo has a relatively strong competitiveness with high private and social profits. Therefore, the 5\% reduction in production yield may not impact on these indicators. The $1 \%$ increase of coconut production yield is relatively small and may not affect on the private and social profits of the crop. The comparative advantage indicators of pomelo and coconut are almost unchanged (Table 3).

Water and land charges: In general, water and land charges (or taxes) are important parts of inputs costs of agricultural production systems. Vietnam's farmers used to pay for the charges before. The water and land charges are currently supported by the government recently while the society generally still bears these costs. The study assumes that rice, coconut, and pomelo farmers pay for the charges and calculates the comparative advantage indicators of these crops. The results present that the rice private producer gets a loss or negative profit if they have to pay for water and land charges. The private profitability of coconut and pomelo sectors slightly decrease. The comparative advantage indicators of rice, coconut, and pomelo are almost unchanged.

The parameters of output prices: Coconut and pomelo production systems still obtain the comparative advantages by all indicators when the output prices of coconut and pomelo products decrease by $20 \%$. On the other hand, rice crop is not profitable for a private producer at a declining level of $10 \%$ while it is still profitable for society at a declining level of $20 \%$. In general, the comparative advantage of the rice crop is relatively sensitive to the changes in rice export price. Whereas, the comparative advantages of coconut and pomelo crops are definitely stable under the changes in their export prices in the assuming scope.

The parameters of fertilizer prices: The comparative advantage indicators of rice, coconut, and pomelo are still higher than the neutral points under the scenario of changing the fertilizer prices in the assuming scope. In overall, the changes in the fertilizer prices have small impacts on the competitiveness of rice, coconut, and pomelo.

The parameters of real effective exchange rates: The changes of the real effective exchange rates, 


\begin{tabular}{llcccc}
\hline No. & Indicators & Unit & Rice & Coconut & Pomelo \\
\hline 1 & Private profitability (PP) & USD & -184 & 1,519 & 15,803 \\
2 & Social profitability (SP) & USD & 506 & 3,475 & 23,991 \\
3 & Domestic resource cost (DRC) & & 0.77 & 0.38 & 0.13 \\
4 & Social cost-benefit (SCB) & & 0.82 & 0.42 & 0.16 \\
\hline
\end{tabular}

Source: own calculation based on the primary data (2017)

Table 3: The sensitivity analysis of comparative advantages by the climate change.

in principle, should affect on the social comparative advantage indicators only. The result shows that the changes of this variable in the assuming scope do not make these agricultural production systems to be uncompetitive.

In summary, rice production system is probably the weakest comparative advantage one and also the most sensitive to climate change, fluctuation of market prices and policy. Pomelo production system has the strongest comparative advantage and relatively stable to the changes in market and policy conditions. It is, however, potential to be relatively affected by climate change. Coconut has a comparative advantage and definitely stable production system to the changes in climate and other market and policy conditions. Pomelo results in the greatest private and social profits while coconut can generate a potential coconut processing cluster with stable private and social profits. The results suggest that under climate change and lack of fresh water, pomelo and coconut are likely appropriate alternative crops to rice when they have the better adoptive capacity, especially for coconut, and ensure comparative advantages. If diversity of agricultural commodities is considered, the direct comparison might be difficult, for instant, rice and/or coconut land can be converted for brackish water aquaculture. In this case, changes in agro-ecological characteristics cannot be reserved and lead to difficulty in the valorization of loss or gain in changes of environment and land use models. It may be suggested that farmers and policymakers should convert from rice crop into pomelo and coconut crops for more effective economic and sustainable benefits. However, this conversion should take account of the soil transferring costs and the initial cultivation costs of pomelo and coconut crops. Because pomelo and coconut require arable lands with furrow drains and mounds. It takes about four to five years to harvest pomelo and coconut with many cost and investment while there is no income in this period for farmers from the trees.
Consistency of different approaches in measuring agricultural competitiveness

In addition, this study measure trade competitiveness of these sectors by using RCA, RTA, and NRCA (following Hoang et al., 2017a, b) to understand the consistency of different approaches in measuring agricultural comparative advantage. PAM indicators indicate that pomelo is the strongest competitive, coconut is the medium competitive, and rice the weakest competitive while the trade indices show the different results that rice the strongest competitive, coconut is the medium competitive, and pomelo is uncompetitive (Table 4). These results seem to be contrasting to the economic literature which considers PAM indicators as the determinants of the trade performance competitiveness. In other words, the sectors with strong production comparative advantages will obtain stronger export competitiveness on the world markets, and vice versa. The potential explanation for this theoretical and practical issue is as follows.

It is the matter of the definitions of the competitiveness of a nation and a sector. A country can be defined as to have a comparative advantage in a sector if the country can produce the product with higher productivity, lower cost, and lower price finally and obtain higher relative market shares on the world markets. The product of a country with a comparatively lower price in the global market will achieve higher relative market shares in comparison with other countries and commodities. In this case, higher relative market shares (or comparative advantage) and lower price are synonymous. On the other hand, the competitiveness can be also defined as the ability of a nation, a sector, and a company to generate, while being and remaining exposed to international competition, relatively high and rising income and factor employment levels on a sustainable basis. In this definition, the competitiveness is synonymous with or positively related to higher profit and income for farmers. In order to have higher profit and income, farmers and producers should obtain higher prices, higher productivity, 


\begin{tabular}{lccccc}
\hline & RCA & RTA & NRCA & DRC & SCB \\
\hline Rice & 5.88 & 6.25 & 0.86 & 0.63 & 0.71 \\
Coconut & 1.56 & 1.60 & 0.02 & 0.38 & 0.42 \\
Pomelo & 0.23 & -0.09 & -0.01 & 0.13 & 0.15
\end{tabular}

Source: own calculation based on the data of ITC and the primary data (2017)

Table 4: Comparing the competitiveness of different agricultural sectors by various indices.

and lower costs. As the result, the higher prices will lead to the stronger competitiveness of a nation under the constant conditions in this context.

In this empirical study, rice obtains the strongest trade competitiveness while it has the weakest production comparative advantage. The product is a main production system of Vietnam with large cropland areas and export shares in total exports. Rice price is dependent on the world rice price and relatively low. Moreover, Vietnam's rice production system employs the traditional technology with small-scale farms, low-skilled workers, and increasing input costs of fertilizers and pesticides. On the other hand, pomelo has the comparative disadvantage in export measured by the trade performance indices while it obtains the relatively strong competitiveness in production measured by PAM indicators. Da Xanh pomelo is a specialty product of Ben Tre with outstanding characteristics and quality which are preferred and highly evaluated by the local consumers and they are willing to pay a high price. It is, however, difficult to export the fruit to the world markets with a high price and local special characteristics. Coconut is a sustainable crop production system as it provides material input for the processing industry and can be cultivated in a harsh condition. In summary, it depends on the research objectives to define and measure competitiveness by trade (or market), economic (production), social, and environmental indicators or/and perspectives.

\section{Conclusion}

The study aims to investigate the competitiveness of these alternative crops under similar agro-ecological conditions and the contexts of climate and market changes. The results, in general, indicate that pomelo achieves the strongest comparative advantage with DRC of 0.13 and $\mathrm{SCB}$ of 0.15 , coconut obtains the medium comparative advantage with DRC of 0.38 and SCB of 0.42 , while rice has the weakest comparative advantage with DRC of 0.63 and SCB of 0.71 . The sensitivity analysis of the comparative advantages show that: First, for the case of the drought and salinity intrusion in 2016, rice becomes non-profitable at the market price while the sector is still competitive at the social price. Meanwhile, the comparative advantage indicators of coconut and pomelo seem to be insignificantly changed. Second, if rice, coconut, and pomelo producers have to pay the water and land charges rice producer will get lost while the ones growing coconut and pomelo still obtain good profits. Nevertheless, the payments of the water and land charges to the government do not impact on the comparative advantage indicators. Finally, the different scenarios of sensitive analysis confirm that rice output price decreases make the producers get lost at the point of $10 \%$. Nevertheless, all other comparative advantage indicators are relatively stable in the nature or in the interval $[0,1]$ in the assuming scopes. In general, coconut crop is the most stable while rice is the most sensitive to the changes of climate and market conditions. This may suggest that farmers and policymakers may consider converting from rice crop into and adopting pomelo and coconut crops for more effective economic and sustainable benefits. However, this conversion should take account of the soil transferring costs and the initial cultivation costs of pomelo and coconut crops.

In spite of some limitations, DRC, SCB, and other competitiveness indicators in PAM model are useful analytic tools in detecting comparative advantages and dynamics of comparative advantages under environmental and market changes. They are appropriate to support farmers, agribusiness enterprises, and policymakers in decisionmaking process. However, to effectively use this approach, it is essential to combine with sensitive analsysis, collect accurate data of all stakeholders from the upstream to the downstream of value chains which are not available in Vietnam's secondary database. In addition, conversion of market prices to shadow prices must be carefully taken into accounts under real social economic situations.

The comparison analysis result between production and trade approaches indicates that production indicators and trade indices explain different rankings of competitiveness of the sectors under study. This result, however, is still consistent 
with the economic literature. This is the matter of competitiveness definitions and research objectives. The production indicators focus on the unit profitability and income while the trade indices tress on the relative market share and power.

\section{Acknowledgments}

This research is gratefully granted by the University of Economics Ho Chi Minh City (UEH).

Corresponding authors

Van Viet Hoang

University of Economics Ho Chi Minh City

59C Nguyen Dinh Chieu, District 3, Ho Chi Minh City, Vietnam

Phone: +84914818 781,Email: viet.hoang@ueh.edu.vn

\section{References}

[1] Adeoye, I. B. and Oni, O. A. (2014) "Competitiveness and Effects of Policies on Plantain Production Systems in Southwestern Nigeria”, AGRIS on-line Papers in Economics and Informatics, Vol. 6, No. 4, pp. 3-13. ISSN 1804-1930.

[2] Amirteimoori, S. and Chizari, A. H. (2008) "An Investigation of Comparative Advantage of Pistachio Production and Exports in Iran”, Journal of Agricultural Science and Technology, Vol. 10, No. 5, pp. 395-403. ISSN 1680-7073.

[3] Balassa, B. (1965) "Trade liberalisation and "revealed" comparative advantage", The Manchester School, Vol. 33, No. 2, pp. 99-123. DOI 10.1111/j.1467-9957.1965.tb00050.x.

[4] Beghin, J. and Fang, C. (2002) "Protection and trade liberalization under incomplete market integration", American Journal of Agricultural Economics, Vol. 84, No. 3, pp.768-773. ISSN 00029092. DOI 10.1111/1467-8276.00335.

[5] Ben Tre Statistics Office (2017) "Ben Tre Statistics Yearly Report".

[6] Bruno, M. (1972) "Domestic resource costs and effective protection: Clarification and synthesis", Journal of political economy, Vol. 80, No. 1, pp. 16-33. ISSN 00223808. DOI 10.1086/259858.

[7] Buckley, P., Pass, L. P. and Prescott, K. (1988) "Measures of International Competitiveness: A Critical Survey", Journal of Marketing Management, Vol. 4, No. 2, pp. 175-200. ISSN 0267-257X. DOI 10.1080/0267257X.1988.9964068.

[8] Bui, D. H., Makin, A. J., and Ratnasiri, S. (2017) "Is Vietnam's exchange rate overvalued?", Journal of the Asia Pacific Economy, Vol. 22, No. 3, pp. 357-371. ISSN 1354-7860. DOI 10.1080/13547860.2016.1270041.

[9] Cai, J., Leung, P. S. and Hishamunda, N. (2009) "Assessment of comparative advantage in aquaculture: Framework and application on selected species in developing countries", FAO Fisheries and Aquaculture Technical Paper, No. 528, pp.73, ref. 46. ISSN 2070-7010.

[10] Darvas, Z. (2012) "Real effective exchange rates for 178 countries: a new database", Working Paper 2012/06, Bruegel

[11] Estudillo, J. P., Fujimuram, M. and Hossain, M. (1999) "New rice technology and comparative advantage in rice production in the Philippines", The Journal of Development Studies, Vol. 35, No. 5, pp. 162-184. ISSN 0022-0388. DOI 10.1080/00220389908422596.

[12] Gorton, M. and Davidova, S. (2001) "The International Competitiveness of CEEC Agriculture", The World Economy, Vol. 24. No. 1, pp. 85-200. ISSN 1467-9701. DOI 10.1111/1467-9701.00351.

[13] Gorton, M., Davidova, S., Banse, M. and Bailey, A. (2006) "The international competitiveness of Hungarian agriculture: Past performance and future projections", Post-communist economies, Vol. 18, No. 1, pp. 69-84. ISSN 1463-1377. DOI 10.1080/14631370500505289.

[14] Gorton, M., Hubbard, C. and Ferto, I. (2013) "Theoretical background and conceptual framework", COMPETE working paper, N2 December 2013. 
[15] Hoang, V. V., Tran, K. T. and Tu, B. V. (2017a) "Assessing the Agricultural Competitive Advantage by the RTA index: A Case Study in Vietnam ", AGRIS on-line Papers in Economics and Informatics, Vol. 9, No. 3, pp. 15 - 26. ISSN 1804-1930. DOI 10.7160/aol.2017.090302.

[16] Hoang, V. V., Tran, K. T., Tu, B. V., Nguyen, V. N. and Nguyen, A. Q. (2017b) “Agricultural Competitiveness of Vietnam by the RCA and the NRCA Indices, and Consistency of Competitiveness Indices", AGRIS on-line Papers in Economics and Informatics, Vol. 9, No. 4, pp. 53-67. ISSN 1804-1930. DOI 10.7160/aol.2017.090406.

[17] International Monetary Fund (IMF) (2016) "IMF Country Report No. 16/240".

[18] International Trade Centre (ITC, 2017) [Online]. Available: http://www.intracen.org/ [Accessed: March 2018].

[19] Latruffe, L. (2010) "Competitiveness, productivity and efficiency in the agricultural and agrifood sectors", OECD Food, Agriculture and Fisheries Working Paper, No. 30, OECD Publishing. ISSN 18156797. DOI 10.1787/5km91nkdt6d6-en.

[20] Liefert, W. (2002) "Comparative (dis?) advantage in Russian agriculture", American Journal of Agricultural Economics, Vol. 84, No. 3, pp. 762-767. ISSN 00029092. DOI 10.1111/1467-8276.00334.

[21] Makosholo, M. L. and Jooste, A. (2006) "The comparative advantage of selected longterm crops in Lesotho", Agrekon, Vol. 45, No. 2, pp. 173-184. ISSN 0303-1853. DOI 10.1080/03031853.2006.9523741.

[22] Mane-Kapaj, A., Kapajb, I., Chan-Halbrendtc, C. and Totojanid, O. (2010) "Assessing the comparative advantage of Albanian olive oil production", International Food Agribusiness Manage Review, Vol. 13, No. 1, pp. 15-26. ISSN 1559-2448.

[23] Mantau, Z. and Nuriantono, N. (2014) "Analysis of competitiveness of lowland rice farming in Indonesia: Case study of Bolaang Mongondow District, North Sulawesi Province", Journal of Economics and International Finance, Vol. 6, No. 4, pp. 85-90. ISSN 2141-6672. DOI 10.5897/JEIF2013.0520.

[24] Martinez, E. R., Tadeo, A. J. P. and Estruch, V. (2008) "The policy analysis matrix with profitefficient data: evaluating profitability in rice cultivation", Spanish Journal of Agricultural Research, No. 3, pp. 309-319. ISSN 1695-971X.

[25] Masters, W. A. and Winter-Nelson, A. (1995) "Measuring the comparative advantage of agricultural activities: Domestic resource cost and the social cost-benefit ratio", American Journal of Agricultural Economics, Vol. 77, pp. 243-250. ISSN 00029092. DOI 10.2307/1243534.

[26] Michalek, J. (1995) "An application of the Policy Analysis Matrix for an evaluation of agricultural policies in the Slovak Republic", Oxford Agrarian Studies, Vol. 23, No. 2, pp. 177-196. ISSN 1360-0818. DOI 10.1080/13600819508424097.

[27] Mohanty, S., Fang, C. and Chaudhary, J. (2003) "Assessing the Competitiveness of Indian Cotton Production: A Policy Analysis Matrix Approach”, The Journal of Cotton Science, Vol. 7, pp. 65-74. ISSN 1524-3303.

[28] Monke, E. A. and Pearson, S. R. (1989) "The Policy Analysis Matrix for agricultural development", Ithaca and London: (No. 04; HD1415, M5) Cornell University Press.

[29] Morrison, J. and Balcombe, K. (2002) "Policy analysis matrices: beyond simple sensitivity analysis", Journal of International Development, Vol. 14, No. 4, pp. 459-471. ISSN 1099-1328. DOI 10.1002/jid.887.

[30] Pearson, S. R., Akrasanee, N. and Nelson, G. C. (1976) "Comparative Advantage in Rice Production; A Methodological Introduction", Food Research Institute Studies, Vol. 15, pp. 127-37.

[31] Tsakok, I. (1990) “Agricultural Price Policy: A Practitioner's Guide to Partial Equilibrium Analysis", Ithaca: Cornell University Press. 
[32] Vietnam's General Statistics Office (2018). [Online]. Available: https://www.gso.gov.vn. [Accessed: March 2018].

[33] Vollrath, T. (1991) "A theoretical evaluation of alternative trade intensity measures of revealed comparative advantage", Review of World Economics, Vol. 127, No. 2, pp. 265-280. ISSN 1610-2878/1610-2886. DOI 10.1007/BF02707986.

[34] Yao, S. (1997a) "Comparative advantages and crop diversification: a policy analysis matrix for Thai agriculture", Journal of Agricultural Economics, Vol. 48, No. 2, pp. 211-222. ISSN 1477-9552. DOI 10.1111/j.1477-9552.1997.tb01146.x.

[35] Yao, S. (1997b) "Rice production in Thailand seen through a policy analysis matrix", Food Policy, Vol. 22, No. 6, pp. 547-560. ISSN 0306-9192. DOI 10.1016/S0306-9192(98)00007-4.

[36] Yu, R., Cai, J. and Leung, P. S. (2009) "The normalized revealed comparative advantage index", The Annals of Regional Science, Vol. 43, pp. 267-282. ISSN 0570-1864. DOI 10.1007/s00168-008-0213-3.

[37] Zheng, S., Lambert, D., Wang, S. and Wang, S. (2013) "Effects of Agricultural Subsidy Policies on Comparative Advantage and Production Protection in China: An Application with a Policy Analysis Matrix Model", The Chinese Economy, Vol. 461, pp. 20-37. ISSN 1097-1475. DOI 10.2753/CES1097-1475460102. 